\title{
EL LITORAL Y EL ESTADO BOLIVIANO ANTE EL DESAFÍO DEL GUANO'1
}

\author{
The Litoral and the Bolivian State \\ facing the challenge of guano
}

\author{
Pol Colàs \\ Universitat de Barcelona, España
}

\begin{abstract}
Resumen: En el siguiente artículo pretendo mostrar, por un lado, la relación del Estado boliviano con el guano atacameño y el desempeño de la legislación monopolista y el contrato económico para su explotación con dos empresas británicas; y, por otro lado, la respuesta de la localidad ante el despliegue de la autoridad central por su territorio y la llegada de la frontera económica capitalista sobre un recurso del que había una larga tradición en su explotación. Todo ello resultó en un choque de modelos, en una lucha entre legitimidades para imponer un proyecto propio con el que gestionar el negocio del guano y sus beneficios.
\end{abstract}

Palabras clave: guano, liberalismo, Atacama, siglo XIX.

\begin{abstract}
In this paper, my aim is to analyze, on the one hand, the relationship between the Bolivian State and guano from Atacama and the performance of the monopolistic legislation and economic contracts for its exploitation with two British companies; on the other hand, the local response to the deployment of the central authority in its territory and the advance of the capitalist economic frontier over a resource for which there was a long tradition of exploitation. What resulted was a clash of models, and a struggle between legitimacies to impose their own project to manage the guano business and its benefits.
\end{abstract}

Keywords: guano, liberalism, Atacama, 19th century.

1. Este trabajo se inscribe en el proyecto de investigación $I+D+i$ del Ministerio de Ciencia e Innovación (Ref. PID2019-103879GB-100) desarrollado en el seno del TEIAA (2017SGR26), grupo de investigación consolidado por el Comissionat per a Universitats i Recerca del DIUE de la Generalitat de Catalunya. Una versión preliminar fue presentada en el XIX Congreso Internacional de la Asociación Española de Americanistas «Los caminos de América», celebrado en la Universidad de Santiago de Compostela del 14 al 16 de junio de 2021. Agradezco a los participantes y a los evaluadores sus comentarios, que han contribuido a mejorar este trabajo. 


\section{Introducción}

La revolución agrícola de la Europa decimonónica no puede ser entendida sin el guano. Situadas en grandes depósitos en la costa del Pacífico de Perú y Bolivia, estas acumulaciones de excrementos avícolas se manifestaron históricamente en un momento clave y pronto el mercado transatlántico absorbió la producción (Newell, 1973; Chorley, 1981). Por ello, durante las décadas de 1830 y 1840 el guano experimentó un notable auge en su extracción, comercialización y uso como fertilizante. Este movimiento potenció, sobre todo, la economía de Perú, país donde se situaban la mayoría de los yacimientos y para el cual el boom, que pudo ser calificado de poco menos que milagro, puso las bases del Estado nacional (Gootenberg, 1989: 68-99; Bonilla, 1994 [1974]).

Y aunque esto es cierto, se trata de una visión que parte del eurocentrismo. Enfocada en la problemática de la expansión del poder económico desde el corazón del capitalismo mundial que suponía la Europa Occidental decimonónica, obvia el hecho de que el guano no fue «descubierto». Para el trabajo presente, acotado en el espacio atacameño, conviene constatar la larga tradición en la explotación de guano, que data desde, como mínimo, el Horizonte Medio (5001000 d. C.). De hecho, el uso del guano pudo haber sido trasladado por los locales al Altiplano a través de contactos con la cultura tiahuanaco y redes comerciales de larga duración (Knudson, 2007; Uribe et al., 2016). Pasados los traumáticos años de la conquista, en tiempos del coloniaje, varios cronistas dieron cuenta de la continuidad en la fertilización de las tierras de cultivo con el uso de guano avícola (Cajías, 1975: 17; Julien, 1985; Cushman, 2018). En concreto, Cieza de León ofreció una descripción de los trabajos de sociedades atacameñas, de los valles de Nazca, Tarapacá y el río llo:

\footnotetext{
Cerca de la mar, en la comarca de estos valles, hay algunas islas bien pobladas de lobos marinos. Los naturales van a ellas en balsas, y de las rocas que están en sus altos traen gran cantidad de estiércol de las aves para sembrar sus maizales y mantenimientos, hallándolo tan provechoso que la tierra se para con ello muy gruesa y fructífera, siendo en la parte que lo siembran estéril; por que si dejan de echar deste [sic] estiércol, cogen poco maíz, y no podrían sustentarse si las aves, posándose en aquellas rocas de las islas de suso dichas, no dejasen lo que después de cogido se tiene por estimado (Cieza de León, 1554: 194-195).
}

Poblaciones diezmadas y en algún caso desperdigadas por el territorio, según lo afirmó Cieza de León, pero aun así todas coincidían en tratar el guano como un artículo preciado por sus propiedades fertilizantes. Garcilaso, por su parte, relató cómo en el Tahuantinsuyo, durante la siembra anual de maíz, era usual beneficiar "con agua y estiércol» las huertas y campos (Garcilaso de la Vega, 1959 [1609]: 216). En tal caso, los desechos podían ser humanos y de ganado, pero los más apreciados eran los «de los pájaros marinos», en especial, entre Arequipa y Tarapacá, y no tanto en el interior por la dificultad en su desplazamiento. Las islas de donde se extraían estaban vigiladas por orden del Inca en tiempos de cría de las aves bajo pena de muerte al intruso, dada la importancia central de la formación de guano para la cosecha (Ibídem: 220221). 
Si bien son descripciones que impiden ser categórico, lo expuesto permite afirmar la existencia de una tradición guanera atacameña y de cierto comercio con el Altiplano (Villalobos, 1979: 64). Parece evidente que este desecho fue un producto de importancia antes del dominio inca, durante la época de la autoridad imperial cuzqueña y a posteriori, por lo que no solo su uso fue conveniente, sino que además sus efectos beneficiosos en la cosecha lo convirtieron en una costumbre territorial. Sea como fuere, podría ser imposible solidificar tales afirmaciones con datos específicos y empíricos más allá de las crónicas coloniales por la manifiesta falta de fuentes, aunque nuevas investigaciones hayan hecho avances al respecto a través del uso de nuevas tecnologías vinculadas con la bioarqueología (Szpak et al., 2012: 3722).

Nada indica que la relación de la población local con el guano cambiase durante los años finales de la colonia y los inicios de la etapa republicana. La continuidad en el uso del abono siguió su curso hasta encontrarse con el despliegue del poder político y el avance de la frontera económica por los áridos parajes atacameños. La llegada del boom guanero fue traumática, y no solo por la discontinuidad de la tradición agrícola, sino también porque supuso el inicio de una mutación multifacética en Atacama, tanto política, productiva y comercial como en el patrón de asentamiento y en la procedencia de sus habitantes (Méndez-Quirós y Sánchez, 2009). Ante todo, parece que, en la década de 1840, llegaron y se establecieron en la región los pilares del poder liberal; esto es, el control institucional del Estado boliviano en construcción, las empresas guaneras, los migrantes chilenos ${ }^{2}$ y las relaciones de producción capitalistas, y el guano se usó como vector de introducción. Así pues, se dio inicio al proceso de subsunción formal de la población indígena local bajo la abigarrada estructura estatal boliviana, siguiendo las palabras de Zavaleta Mercado (1989), a partir de la destrucción, la reformulación y el renacimiento de la actividad económica regional, en este caso, la guanera, habiendo cambiado durante el proceso de actores, motivaciones y destino de la mercancía, con los atacameños como la única constante, y adaptándose al cambio. El resultado fue la creación de un paisaje político y económico regional con varias capas, donde el despliegue estatal, desde la superior, pretendió, aprovechando el peso del auge guanero, aplastar el equilibrio anterior.

Fue así como el Estado se abrió a la domesticación de Atacama, sobre la base de la utilización de legislación creada para la ocasión y centrada en monopolizar el guano para romper la continuidad histórica en su uso, de manera que pudiera trasladar la totalidad de la producción al ámbito de la exportación; es decir, usando la ley para fundamentar el control sobre un margen territorial legítimamente. ${ }^{3}$ El guano pareció ser, para el gobierno boliviano, un andamio pecuniario sólido con el que catalizar la institucionalización liberal y, en concreto para la administración de José Ballivián (1841-1847) - la abordada en este trabajo-,

2. Desde que su llegada era una petición expresa de empresarios, en este caso, y como veremos, tanto de los cercanos al guano como de los que lo ignoraron.

3. Quijada (2000: 375); Demélas (2003: 234); Irurozqui (2005: 34); Lettieri (2005: 554); Barragán (2007: 116). 
una fuente fiable de recursos en el proceso (fallido tras la caída del presidente en 1847) de imposición de un proyecto nacional. Aunque en estado incipiente, la autoridad del poder político republicano se desplegó por Atacama a través de la ley y forzó los cambios citados firmando una contrata monopolística que limitó la explotación del guano a los designios de dos empresas inglesas, en una clara muestra de fuerza del Estado liberal y de la capacidad de lucha según intereses, en el caso que atañe, eminentemente económicos.

Este proceso implicó un esfuerzo en el despliegue de la fuerza legal, política y económica en similar medida a como fue respondido por la resistencia de la población local y las autoridades intermedias, puntos que pretendo desgranar en este trabajo, insertándolos en una coyuntura histórica atacameña que ha atraído la atención de varios estudios. De hecho, autores como Conti (2008a) y Langer (2018: 235-237) han mostrado el aumento de la importancia comercial en la región durante la década de 1840 y cómo Cobija - antes caladero marginal - tomó el papel de puerto secundario en la vertiente pacífica sudamericana. Atacama se configuró como punto de encuentro de los Andes centrales con Europa, espacio de acceso al mar que daba salida, y surtía con importaciones, al sur de Bolivia y norte argentino. Especial fue la relación con Potosí, que se convirtió en su puerto preferente durante varias décadas (Cajías, 1997: 138; Barragán, 2009: 42; Vargas Mansilla, 2019: 109), y con las ciudades de Salta, Jujuy y Tucumán (Langer, 2018: 238), que años después redirigieron su comercio hacia Valparaíso, en un movimiento que acabó con el potencial mercantil cobijeño y condenó al puerto al reembarque de mercancía hasta su posterior olvido (Conti, 2008b: 42).

La región demostró también su capacidad para acceder a una producción notable en el ámbito de la pesca, aunque estuviera en declive desde la época colonial (Martínez, 1985: 164-165). En pujanza, podían encontrarse actividades económicas como la arriería y la minería. En el caso de los arrieros, se conformaron como figuras fundamentales en la superación del arduo camino desde Cobija hasta Calama, cuello de botella que requirió de cierta especialización para recorrerlo, el cual suponía una dificultad clave que solo podían salvar las mercancías a partir del trabajo de estos individuos locales. ${ }^{4}$ La minería fue una actividad de éxito creciente $y$, en consecuencia, con una demanda de mano de obra ascendiente, que acabó por absorber poblaciones enteras y rompió el sentido de comunidad en la región, además de que demandó una ingente inmigración chilena por parte de los inversores, entre ellos, el comerciante y empresario español José María Artola (Platt, 2016; Conti, 2019; Letelier Cosmelli y Castro Rojas, 2019: 163) y el francés Domingo Latrille (Galaz-Mandakovic y Owen Palma, 2015), aunque este no fuera el único - ni el principal - motivo de su llegada.

En definitiva, son muchos los estudios que permiten concebir el Departamento del Litoral como un territorio que se resignificó durante el devenir del siglo XIX, desestructurando modos de vida tradicionales no solo a través de la legislación estatal relacionada con el guano, sino también mediante varias vías de

4. Aldunate et al. (2008: 107); Godoy (2013: 131); Letelier Cosmelli (2016: 225); Letelier Cosmelli y Castro Rojas (2017: 132-134); Colàs (2021a: 13, 20). 
cambio (Barros, 2008). En todo caso, considero que la legislación y los trabajos guaneros, por sus implicaciones y consecuencias, son centrales para concebir el acaecer histórico regional, comprender las formas de relación entre el Estado y el margen territorial y del despliegue del poder político central por la vasta geografía boliviana.

No obstante, la ineficiencia política en los márgenes que mostraron las incipientes repúblicas latinoamericanas (Bohoslavsky y Godoy, 2010) permitió cuestionar el proceso iniciado y facilitó la convivencia de actividades regladas con otras ilícitas, de la ley con su contrapeso, por lo que desde el poder central se vivieron serias dificultades para evitarlo, para aplastar las heterodoxias dentro de la pretensión de erección de un modelo liberal viable. En particular, alrededor de las guaneras de Paquica (al norte de Cobija) y Angamos (en Mejillones), pero también por la mayoría de las guaneras encontradas en la superficie del territorio estudiado, se articularon múltiples estrategias para el acceso al recurso en paralelo al monopolio inglés. Reconstruir la estrategia del Estado y de las compañías con acceso al guano, y hacer una aproximación a la de los grupos locales que no lo tuvieron legalmente, es el objetivo de este trabajo.

La estructura del texto pasa por una primera parte en la que abordo la relación guano-Estado, con el Ejecutivo y con sus intereses, así como los de las compañías inglesas que accedieron a la explotación, y muestro cómo las decisiones gubernamentales tuvieron traducción práctica en el devenir histórico de ese territorio marginal de Bolivia que es el atacameño. En la segunda parte, me centro en la respuesta local y en la continuidad de la tradición guanera en la región, simultánea a la inserción de otros personajes en actividades afines al sistema económico normativo.

Las principales fuentes son: primero y fundamentalmente, las localizadas en el Archivo y Biblioteca Nacionales de Bolivia (en adelante, ABNB), en concreto en los varios fondos relativos al poder ejecutivo bajo la presidencia de José Ballivián; he contado también con fuentes hemerográficas localizadas en la Universidad Mayor de San Andrés de La Paz (en adelante, UMSA) y con la colección oficial de leyes que se encuentra en el Archivo Histórico de la Asamblea Legislativa Plurinacional. Por su naturaleza, estas fuentes, ya oficiales, ya cercanas al poder, permiten tratar la temática del guano como vía para abordar las disquisiciones históricas en torno a la construcción del Estado liberal decimonónico, y he contado tanto con documentos que relatan la acción estatal como con informes de sus consecuencias e impactos. Sin embargo, escoger documentos oficiales implica una mayor dificultad para encontrar las respuestas propias de los actores del Litoral, en ocasiones escondidas entre marañas de textos administrativos, lo que explica la brevedad comparativa de la segunda parte del artículo, aunque no impide la presentación de datos específicos y útiles a los objetivos de este trabajo.

\section{Guano y Estado boliviano}

Pretendo analizar aquí la política del gobierno de José Ballivián respecto al guano, ante todo en relación con las contratas monopolísticas con empresas britá- 
nicas, pero también en torno a cómo se legitimó la decisión, legislativa y discursivamente, y cuáles fueron sus consecuencias. ${ }^{5}$

El gobierno de Ballivián tuvo el afán de dar una salida al guano desde su primer momento en el asiento del poder ejecutivo. En cierto modo, pareció una urgencia heredada del breve mandato de José Miguel de Velasco, quien en marzo de 1841 había firmado una contrata con la familia cochabambina de los Sanzetenea, concerniente a las guaneras del norte de Cobija (Conti, 2002: 8587; Colàs, 2021a: 8), ${ }^{6}$ mientras que en abril se decidió el arriendo de los yacimientos sureños a inversores ingleses. ${ }^{7}$ El auge de la Regeneración en junio de ese mismo año volvió a dar la presidencia del país a los partidarios del llamado supremo protector de la Confederación Perú-Boliviana, Andrés de Santa Cruz, con lo que se truncó la autoridad de Velasco, se acabó con las contratas y se inició el proceso histórico que desembocó en el acceso y consolidación de José Ballivián en el poder tras la victoria en la batalla de Ingavi. ${ }^{8}$

Las consecuencias de la firma fallida con los Sanzetenea se apreciaron durante el mandato de Ballivián y, de hecho, en 1842 pareció retomarse el contrato anterior para proceder al cobro del arrendamiento guanero. ${ }^{9} \mathrm{La}$ coyuntura demandaba ingresos importantes y rápidos a causa de las dificultades que el ejército boliviano estaba encontrando para acabar la guerra peruano-boliviana, con los perjuicios consiguientes para el Tesoro. Sin embargo, más allá de algunas entradas puntuales de numerario a principios de $1842,{ }^{10}$ la compañía cochabambina desapareció del escenario guanero, y la rescisión contractual fue justificada por el gobierno con el argumento de que el documento firmado por Velasco era lesivo para los intereses del país. ${ }^{11}$ Fue a partir de entonces cuando los Sanzetenea trataron de ayudar al Ejecutivo a encontrar sociedades que estuvieran interesadas en el negocio y fueran capaces de gestionarlo.

Desaparecida la contrata firmada por Velasco, empezaron de forma inmediata negociaciones con compañías extranjeras. En el gobierno existía la convicción de que, dada la escasez de capitales propios para invertir que acuciaba la

5. Considerando la relación estrecha entre aprobación de legislación y control territorial, y también económico, político y social, como afirma, entre otros autores, Quijada (2000).

6. Comunicación del prefecto del Litoral al Ministerio del Interior, en ABNB, Ministerio del Interior (MI), t. 87, núm. 26, 23 de marzo de 1841.

7. Comunicación del prefecto del Litoral al Ministerio del Interior, en ABNB, MI, t. 87, núm. 26, 16 de abril de 1841.

8. La historiografía tradicional ha hablado largamente sobre la batalla de Ingavi y las repercusiones que tuvo en el devenir del mandato posterior de Ballivián. Algunos ejemplos son: Manuel José Cortés (1861: 159-160), José María Camacho (1896: 128-129) y uno de los personajes principales de las letras bolivianas de principios de siglo Xx, Alcides Arguedas (1967 [1922]: 110-111). Más recientemente, debe destacarse que tanto Irurozqui (2018: 95-98) como Colàs (2021b) señalan esta victoria como punto de partida para justificar la primacía del Ejecutivo con Ballivián.

9. Comunicación del Tesoro Público de La Paz al comisario general del ejército, en ABNB, MI, t. 91, núm. 8, 26 de febrero de 1842.

10. Carta de Mariano Sanzetenea al Ministerio de Hacienda, en ABNB, Ministerio de Hacienda (MH), t. 86, núm. 14, 19 de marzo de 1842, f. 3.

11. Carta de Mariano Sanzetenea al Ministerio de Hacienda, en ABNB, MH, t. 86, núm. 14, 21 de febrero de 1842, f. 1. 
economía boliviana, era conveniente que el desarrollo del negocio guanero contara con la colaboración del mundo empresarial británico. Este, aprovechando la condición de potencia mundial de su gobierno y con un poderío económico considerable, podría hacer del guano del Litoral un recurso rentable, como se estaba consiguiendo en el Perú. ${ }^{12}$

Hubo dos compañías inglesas que negociaron simultáneamente con el gobierno la firma de una contrata para la explotación y exportación monopolística del guano atacameño: Gibbs Crawley Co. y Myers Bland Co. ${ }^{13}$ Ambas contaban con sede en Liverpool, tenían experiencia de gestión en el comercio del estiércol por encargarse del arriendo de varias guaneras peruanas con un éxito notable en el mercado, como las de las islas Chincha o los islotes de Tarapacá (Ravest Mora, 2008; Mathew, 2009). El proceso para la firma del acuerdo fue largo, tanto que los trabajos de las compañías en el Litoral empezaron antes de la publicación del texto final, a partir del 23 de junio de 1842, gracias a la aprobación parcial de algunos de los artículos de la contrata, aunque a principios de 1844 aún seguía pendiente de finalizarse (Buitrago, 1844). ${ }^{14}$

El acuerdo solo se logró tras el pago de 300.000 pesos por las compañías inglesas al gobierno boliviano, monto al que debieron renunciar, sin posibilidad de reclamación futura; ${ }^{15}$ las empresas fueron también obligadas a abrir la puerta a la concesión posterior de empréstitos cuando el Ejecutivo así lo reclamase. ${ }^{16}$ Las condiciones finales pactadas concedieron el $70 \%$ de los beneficios para el Estado de Bolivia, que acudía al trato con el guano como capital aportado, mientras que el $30 \%$ restante se repartiría de forma equitativa entre las sociedades contratantes. ${ }^{17}$ Es evidente que ambas partes preveían la obtención de grandes beneficios tanto más considerando la experiencia de Gibbs y Myers en la venta del abono peruano. Asimismo acordaron publicitar la entrada del guano boliviano en el mercado a través de ensayos científicos en los que fuera calificado de primera calidad, a la par con el de Chincha, con el objetivo de vencer toda resistencia que los consumidores europeos pudieran tener ante una procedencia desconocida. ${ }^{18}$

12. Carta anónima al Ministerio de Hacienda, en ABNB, MH, t. 86, núm. 14, 12 de febrero de 1842, f. 15.

13. Lo cual fue tomado como un éxito del gobierno en su tarea de difusión de la posibilidad de arriendo de las guaneras, ya que el hecho de que las compañías contratantes fueran dos pudo disminuir el riesgo de estafa, malos hábitos, etc. (Carta anónima a Myers Bland y Cía., en ABNB, MH, t. 86, núm. 14, 13 de septiembre de 1842, f. 14).

14. Carta de Gibbs Crawley y Quirós Allier a Carlos Barroilhet y Wenceslao Paunero, en ABNB, MH, t. 86, núm. 14, 8 de agosto de 1842, f. 23.

15. Aunque fue un pago fraccionado, que daba comodidad a las compañías para poder sufragarlo, a finales de 1842 ya se encontraba satisfecho (Carta de Myers Bland y Cía. a Gibbs Crawley y Cía., en ABNB, MH, t. 86, núm. 15, 30 de septiembre de 1842, f. 20).

16. «Artículos adicionales a la contrata del huano». El Restaurador (Sucre), en UMSA, t. 7, núm. 31, 2 de julio de 1844, pág. 1.

17. Carta anónima al Ministerio de Hacienda, en ABNB, MH, t. 86, núm. 14, 13 de septiembre de 1842, ff. 15r-15v.

18. «Los introductores del huano [sic] Peruano y Boliviano, comisionados para su venta por los Gobiernos de aquellos países [europeos], a quienes los almacenes de este artículo pertenecen, han 
Entre el pago para la aprobación parcial y la finalización de las negociaciones se impulsaron ciertos cambios en la contrata: entre otros, la eliminación de la cláusula por la que la producción boliviana de guano debía igualar a la peruana, señalada como irreal por las compañías contratistas; la capacitación al gobierno para incidir en el proceso de gestión y contabilidad del guano, para asegurar un negocio limpio; y la exención al poder ejecutivo de toda responsabilidad relativa a las deudas y compromisos que pudieran contraer los contratistas con terceros, por lo que se estaban asegurando mayores garantías de beneficio y menos riesgos para el erario. ${ }^{19}$ Otro de los artículos añadidos resultó clave porque dio capacidad a las empresas inglesas para poder suspender las remesas de guano a Europa, con la conformidad del interventor público de guaneras, en caso de pérdidas continuadas u onerosas. ${ }^{20}$ Estos cambios propiciaron el estallido de un clima de euforia en la esfera pública paceña. Ejemplo significativo lo ofrecen los elogios del periódico paceño El Indicador, que destacó la pericia del gobierno en la consecución de un texto beneficioso para el Estado. ${ }^{21}$

El monopolio guanero pudo empezar a desplegarse por el territorio mediante el decreto ejecutivo de 20 de febrero de 1842, cuando la total prohibición de extraer este abono a quien no fuera parte de las compañías contratantes lo legitimó en el corpus legal boliviano. La decisión quedó justificada por el hecho de que «nadie puede alegar título legal sin ofensa ni agravio del eminente derecho de la nación, a la propiedad de las huaneras [sic]»; el Estado, aunque hubiera extractores de guano previos, tenía la potestad de proceder al arriendo de sus yacimientos sin dar explicación a los afectados y, en suma, podía solidificar el nuevo orden a partir de la imposición de penas de hurto y comiso de lo tomado desde aquel momento hasta el fin de la vigencia contractual. ${ }^{22}$ En el ámbito legal, esta decisión acabó con la tradición guanera de la región y dio cobertura al inicio de la explotación extranjera del guano, que el año siguiente fue confirmada por el poder legislativo. ${ }^{23}$

Dicho esto, se trató de una disposición que no evitó que el artículo de la contrata que versaba sobre la suspensión de las remesas del guano terminara por aplicarse ante el poco éxito de su puesta en circulación. ${ }^{24}$ Esta situación desfavorable fue motivada por tres razones: la competencia del guano peruano y la aparición de nuevos yacimientos en otras regiones del orbe; el robo y contra-

creído conveniente, para satisfacción de los consumidores, dar muestras de sus diferentes cargamentos al Dr. Andrés Ure, sujeto bien conocido en el mundo científico por sus conocimientos químicos. Después de muchos esperimentos [sic] elaborados y análisis del mismo, el Dr. Ure ha dado una noticia [positiva] sobre la materia». «Huano». El Restaurador (Sucre), en UMSA, t. 6, núm. 1, 17 de septiembre de 1843, pág. 2.

19. «Huano». El Indicador, La Paz, en UMSA, núm. 16, 2 de agosto de 1844, págs. 1-2.

20. Comunicación de 28 de junio de 1844, en Archivo Histórico de la Asamblea Legislativa Plurinacional (en adelante, AHALP), Colección oficial de leyes, decretos, órdenes y resoluciones supremas que se han expedido para el régimen de la República Boliviana (en adelante, Colección...), vol. 8.

21. «Huano». El Indicador, La Paz, en UMSA, núm. 16, 2 de agosto de 1844, pág. 1.

22. Decreto de 20 de febrero de 1842, en AHALP, Colección..., vol. 7.

23. Ley de 10 de mayo de 1843 en AHALP, Colección..., vol. 8.

24. Comunicación del Ministerio de Hacienda al Ministerio de Relaciones Exteriores, en ABNB, Ministerio de Relaciones Exteriores (MRE), t. 9, 13 de octubre de 1845, f. 32. 
bandeo con implicados entre las autoridades locales y la población, que abordaré en el apartado próximo; y la desconfianza de los consumidores europeos respecto al producto boliviano, pues abastecidos por el guano peruano, del que habían experimentado su eficacia como abono, preferían no arriesgarse al producto boliviano, del que desconocían sus propiedades efectivas. De hecho, no se trataba de temores infundados, pues varios de los primeros lotes del abono atacameño llegados a Inglaterra fueron defectuosos - «no cesan de repetirnos nuestros amigos que el Huano [sic] de Bolivia es sumamente inferior al del Perú»,$-{ }^{25}$ por lo que la resistencia de los europeos al producto boliviano parecía justificada. Tras esa nefasta propaganda inicial, a pesar de los ensayos exitosos posteriores, fue una tarea difícil remontar la mala imagen del guano propio. ${ }^{26}$

Además, por si ello no era suficiente, la explotación del guano era central para el proyecto nacional del general Castilla en Perú (Gootenberg, 1989; BoniIla, 1994 [1974]). Sabemos que en Lima se le dio suma importancia a la generalización del producto en los mercados europeos y a una explotación creciente sin parangón en ningún otro país del globo en la época estudiada, con lo que se obstaculizó la expansión del guano boliviano. Y un nuevo factor que supuso un impedimento a la comercialización de este fue la existencia de guano en la isla de Ichaboe, en la costa occidental del África meridional, de la que tomó posesión el Imperio británico (Craig, 2003: 85-92). La información del hallazgo llegó a Bolivia en $1844 \mathrm{y}$, aunque inicialmente se trató de negar la evidencia, ${ }^{27}$ pronto se hizo patente la llegada a Londres de buques cargados con estiércol africano, de calidad notable. ${ }^{28}$ Sumado al dominio del guano peruano y a la poca salida del boliviano en sus ventas, la llegada del producto africano provocó la saturación del mercado y un drástico descenso en los precios.

En definitiva, en comunicación con el Ministerio de Hacienda la compañía Gibbs Crawley vio con pesar el panorama creado por la competencia global ${ }^{29} \mathrm{y}$ la falta de colocación del guano boliviano:

Las grandes existencias de Huano [sic] de otras procedencias y el empeño de los tenedores de ellas en forzar ventas aun a precios muy bajos militan mucho contra nuestra Empresa y hace quizás más aparente que real la prevención [de los consumidores europeos] contra el huano [sic] Boliviano. ${ }^{30}$

25. Carta de Gibbs Crawley y Myers Bland al Ministerio de Hacienda, en ABNB, MH, t. 86, núm. 15, 15 de diciembre de 1842, ff. 26r-26v.

26. Cabe insistir en el envío continuado de remesas de guano "de una buena calidad» (Carta de Gibbs Crawley y Cía. a la compañía subsidiaria en Bolivia, en ABNB, MRE, t. 16, 19 de abril de 1843, ff. 15r-16v).

27. El inspector de guaneras informó al gobierno que «dos de los buques fletados en aquella plaza [Inglaterra] para cargar huano [sic] de las costas de África, habían vuelto a Inglaterra sin un [...] de esta sustancia», por lo que según su criterio no existía el guano africano (Comunicación del inspector de guaneras al Ministerio de Hacienda en ABNB, MH, t. 96, núm. 17, 30 de enero de 1844, f. 4).

28. Carta de Gibbs Crawley al Ministerio de Hacienda, en ABNB, MH, t. 89, núm. 14, 28 de agosto de 1843.

29. Hubo informaciones de la presencia de guaneras en la Patagonia, lo que el gobierno boliviano vio con preocupación (Aguirre, 1846: 12-13).

30. Carta de Gibbs Crawley y Cía. al inspector de guaneras, en ABNB, MH, t. 104, núm. 17, 29 de mayo de 1846, f. $7 r-v$. 
Fuera aparente o fuera real, las contratas no tuvieron el éxito esperado. El escaso movimiento comercial del guano boliviano pronto se hizo patente y trascendió a la opinión pública a través del periódico oficial del gobierno, El Restaurador. ${ }^{31}$ En agosto de 1846 se publicaron comunicaciones entre los dueños de la compañía Gibbs Crawley, desde Liverpool, y el Ministerio de Hacienda. En ellas, se señalaba la necesidad de congelar las remesas de guano por la saturación del mercado inglés con la llegada de producto peruano y africano y su consecuente bajada de precio, que coartaba su rentabilidad. La consecuencia, según afirmó el señor Gibbs, era que «este negocio no puede ofrecer ya sino mui [sic] tardías esperanzas de algún resultado favorable». ${ }^{32}$

Si bien los resultados fueron inesperados, el análisis histórico se resiste al catastrofismo. Las compañías inglesas pudieron extraer guano de los múltiples yacimientos atacameños (en especial, Angamos y Paquica) gracias a la legislación monopolística. Así, en el período comprendido entre junio de 1842 y septiembre de 1844, ambas empresas registraron la exportación, en 37 buques diferentes, de 12.338 toneladas de guano a Inglaterra (8.471 de Paquica, 2.864 de Angamos y 868 toneladas de guano del resto de las guaneras). De esta cantidad, habían vendido 5.015 toneladas, y tenían las restantes almacenadas en Liverpool o en tránsito desde Cobija. Los gastos arrojaron la cifra de 132.413 pesos, mientras que el producto líquido del negocio fue de 40.485 , a descontar el $70 \%$ correspondiente para el gobierno.$^{33}$ Otra revisión al año siguiente reportó la exportación de más de 21.000 toneladas de guano en medio centenar de buques, a pesar de que bajó el beneficio conseguido con su venta por tener unos precios más ajustados. ${ }^{34}$

Estos datos me permiten afirmar que la decisión del poder ejecutivo de ceder el guano a la iniciativa privada, fuera o no exitosa económicamente, incidió en la realidad del momento con consecuencias concretas derivadas de esa explotación, y supuso entradas para las arcas públicas y movimiento comercial en el puerto de Cobija. Pero también afectó a la población local, que necesariamente se vio envuelta en un cambio en su relación con el recurso, y para la región en sí, a la cual resignificó como paraje de negocio desde donde solidificar la construcción del Estado, convirtiéndola en ejemplo del proceso del despliegue del poder político y económico sobre la base del control territorial.

En este sentido, quiero señalar que una de las consecuencias más claras de la explotación guanera boliviana fue la llegada masiva de migrantes chilenos al Litoral - teniendo en cuenta la debilidad demográfica atacameña (Cajías, 1975: 53) -, atraidos por la demanda de mano de obra en varias empresas $y$, sobre todo, en las

31. Poco antes, la política del guano había sido tímidamente denunciada como poco transparente en: «Huanos». La Época, La Paz, en UMSA, año 1, núm. 19, 22 de mayo de 1845, pág. 2.

32. «Si hubiésemos persistido en pretender nuestros precios, como antes se hallaban prefijados; habríamos recargado el renglón de gastos ecsorbitantes [sic]; y lejos de contar con una certeza de ventaja, hubiéramos debido esponernos [sic] a riesgos mui [sic] evidentes, según todas las actuales apariencias». «Interior». El Restaurador, Sucre, t. 10, núm. 20, 25 de agosto de 1846, pág. 1.

33. «Manifestación de los buques [...]». La Época, La Paz, en UMSA, año 1, núm. 40, 16 de junio de 1845, págs. 2-3.

34. «Resumen jeneral». El Restaurador, Sucre, en UMSA, t. 10, núm. 25, 5 de septiembre de 1846, págs. 3-4. 
guaneras y en el puerto de Cobija. ${ }^{35}$ Este aumento de habitantes trastornó la estructura poblacional de la región y debilitó el peso de los atacameños en el total, ${ }^{36}$ lo cual implicó la marginación de la población local de los puestos de trabajo existentes o futuros - en las minas, en las propias guaneras, etc. - (Illanes, 1997) tanto como lo habían sido previamente de la explotación guanera artesanal.

Los datos de Cajías (1975: 108) muestran que la población local atacameña osciló entre el 50 y el $60 \%$ del total regional entre 1830 y 1840 , mientras que en el mismo período la presencia de chilenos aumentó del 10 al 20\%. Aunque el mismo autor niega la posibilidad de que los extranjeros superasen a los locales durante la citada década, señala que la percepción de la existencia de una mayoría chilena la daba el hecho de que no contaban a los indígenas como ciudadanos (lbídem: 107). Posición diversa fue la sostenida en 1846 por el juez de letras del distrito Litoral, Juan de la Cruz Benavente, quien en un alegato público defendió la instauración de la pena de flagelación en Cobija por ser la única forma de que la mayoritaria población chilena atendiera a las peticiones de las autoridades bolivianas, sobre la base de ver igualadas las penas corporales del derecho boliviano con las de su país de origen. En su libelo, afirmó:

\footnotetext{
Cobija[,] por las desventajas de su situación topográfica, tan conocidas por todos los hombres que saben pensar, es hoi [sic], siento verme en la precisión de decirlo, más que un pueblo boliviano una colonia poblada con inmigrados chilenos. La mayoría de sus habitantes, particularmente la plebe, es chilena (Benavente, 1846: 3).
}

Sin duda, los datos de Cajías son mucho más fiables que los ofrecidos por Benavente; sin embargo, el relato del juez contribuía a la creación de una cierta opinión pública de que los chilenos estaban sustituyendo a los locales en los puestos de trabajo de la región. ${ }^{37}$ La llegada de aquellos migrantes cuestionó, en la práctica, el orden social existente hasta entonces e hizo pensar a los locales (fuera o no cierto, a partir de los datos estadísticos) que podían ser superados demográficamente.

La llegada de la inmigración chilena al Litoral fue consecuencia del despliegue del poder central por el territorio, articulado a través de la destrucción de los equilibrios socioeconómicos anteriores para dar paso al capital internacional. La acción legislativa acabó provocando diversas lógicas sociales, económicas y culturales en un mismo territorio y bajo la misma autoridad estatal, - constante en la historia latinoamericana apuntada por Zavaleta Mercado, (1978) - , con las tensiones e inseguridades que eso supuso. ${ }^{38}$ Así, la migración chilena fue parte

35. Pinto Vallejos (1993); Pinto Vallejos y Valdivia Ortiz de Zárate (1997); Colàs (2021a: 10-11).

36. También Domingo Latrille y José María Artola, y se entiende que parte del resto de la burguesía afincada en el Litoral, de acuerdo con el gobierno central tuvo interés en la llegada de migrantes chilenos.

37. Comunicación del prefecto del Litoral al Ministerio del Interior en ABNB, MI, t. 116, núm. 41, 2 de enero de 1846.

38. Sensación compartida por el gobierno de Ballivián (Comunicación del prefecto del Litoral al Ministerio del Interior en ABNB, MI, t. 97, núm. 52, 27 de agosto de 1843). 
de la estrategia del gobierno y de las compañías guaneras para aumentar la mano de obra, pero fue también consecuencia de las esperanzas puestas en el guano como futuro pilar económico del Estado liberal boliviano. Sin embargo, los diversos problemas a los que se enfrentó el negocio del estiércol avícola trasladaron las tensiones económicas a la población local, que respondió resignificando su relación con el guano, ya fuera ignorándolo u optando por deslegitimar el monopolio.

\section{Guano y Litoral atacameño}

En este apartado quiero centrarme en la reacción de los actores del Litoral al verse excluidos de los beneficios de la explotación del guano por parte del gobierno central. Lo muestro con ejemplos de cierta capacidad de renovación comercial, de cambio o adaptación a la nueva coyuntura, así como de ilegalismos que negaron la legitimidad de la legislación monopolística. Utilizo el término «ilegalismo" conscientemente y de forma expresa, siguiendo el sentido foucaultiano de la palabra, como actividad legalmente prohibida, más tolerada, ya sea por incapacidad del Estado de actuar en su contra, o por intereses cruzados de las instituciones intermedias (Foucault, 2009 [1976]: 297-342).

En realidad, pudo haber una tercera vía entre ignorar el negocio del guano e insertarse en él de manera ilegal, como pudo ser la presión para desmonopolizarlo. En 1842 se publicó una larga queja al respecto en El Restaurador, argumentando que, en el caso de que los bolivianos hubieran sabido que el control sobre el guano iba a ser subastado, habrían surgido propuestas capaces de competir con las extranjeras. ${ }^{39}$ Fuera por hermetismo del Ejecutivo boliviano o por incapacidad de la burguesía local, el negocio no solo quedó en manos británicas sino que, además, cuando en el ocaso de la administración de Ballivián se reabrió la posibilidad de firmar una contrata con actores diferentes, la llamada del gobierno fue ignorada. Solo un empresario boliviano acudió a ella para conseguir una nueva contrata a mediados de 1847, el comerciante potosino José Avelino Aramayo, que presentó competencia a las compañías inglesas. Sin embargo, su aparición fue funesta para los intereses gubernamentales, ya que cuando parecía que iba a desbancar a la propuesta de Gibbs Crawley Co. y Myers Bland Co. y estos desistieron, Aramayo se retiró de la puja argumentando que se veía obligado a tomar esa decisión debido a la poca productividad demostrable de las guaneras bolivianas ${ }^{40}$ Ninguna compañía, pues, se benefi-

39. En el artículo citado, sus autores se permitieron proponer cambios en la explotación guanera o alternativas al modelo monopolista: «Pudieron también haber distribuido entre los Bolivianos los terrenos con huano [sic] en pequeñas fracciones; a unos en premio de sus servicios en lugar de darles destinos que no supiesen desempeñar, a otros en clase de venta, o en fin permitir su libre esplotación [sic] a los nacionales, estableciendo un derecho de estracción [sic] bien calculado». «Huano». El Restaurador, Sucre, en UMSA, t. 4, núm. 4, 21 de abril de 1842, pág. 5.

40. Carta de Joaquín Aguirre al Ministerio de Hacienda, en ABNB, MH, t. 113, núm. 21, 28 de mayo de 1847, f. 2; carta del ministro de Hacienda a Joaquín Aguirre, en t. 112, núm. 40, 19 de septiembre de 1847, ff. 4r-4v. 
ció del concurso en el último año de gobierno de José Ballivián, cuestión que, si bien fue importante para el devenir histórico de la relación del Estado con el guano, no deja de ser anecdótica en este trabajo.

Como he mostrado en el apartado anterior, el régimen de monopolio existente sobre el guano entre 1843 y 1847 provocó la marginación de los habitantes del Litoral de su explotación directa -más allá de trabajar como peones o mayordomos en las guaneras junto con migrantes chilenos $-{ }^{41}$ y provocó la reacción de aquellos a través de dos vías: al principio, ignorar el guano y, después, prescindir de la legislación monopolista, como vamos a ver a continuación.

En primer lugar, hubo cierto interés en la inversión y formación de capitales propios para locales o gentes radicadas en el Departamento del Litoral. Pionero en ello fue el comerciante y minero francés Domingo Latrille, quien, de hecho, empezó sus andanzas comerciales alrededor del guano atacameño, explotándolo con trabajadores locales tradicionales y vendiéndolo en Valparaíso (GalazMandakovic y Owen Palma, 2015: 68). Su historia fue accidentada, ya que no tuvo constancia de la firma de la contrata monopolística a tiempo y prosiguió con la explotación en la zona de Mejillones, lo que determinó su detención por impago de aranceles, comercio prohibido y fraude en la exportación de 305 toneladas de guano a 50 pesos por tonelada (Colàs, 2021a: 9). ${ }^{42}$ En consecuencia, el gobierno francés amagó con bloquear el puerto de Cobija para forzar la liberación de aquel, a lo que las autoridades bolivianas respondieron amistosamente. Latrille permaneció en el Litoral y se convirtió en un minero de éxito con la fundación de la Compañía Minera de Tocopilla, de la que fueron socios su hermano Máximo, Guillermo Billinghurst y Carlos Barroilhet (Galaz-Mandakovic, 2017). ${ }^{43}$

El de Latrille es un ejemplo de cómo la firma de la contrata extranjera afectó a los comerciantes radicados en el Litoral, tanto locales como foráneos. Ante esa nueva realidad, trataron de buscar nuevas vías de desarrollo económico legales, ya fuera a través del comercio interno, de la arriería (Conti y Sica, 2011; Letelier Cosmelli, 2016; Langer, 2018), de la minería, de la actividad logística de apoyo al gran comercio o de la opción de ser intermediarios de las compañías contratistas. ${ }^{44} \mathrm{La}$ importancia que adquirieron tales actividades fue notable, lo que explica la presión hecha desde la localidad a los poderes fácticos del Estado para conseguir el monopolio boliviano de almacenes extranjeros en Cobija, que debía favorecer a los comerciantes y arrieros propios de la región, dinamizando el puerto como punto de intercambio marítimo y terrestre. ${ }^{45}$

41. Comunicación del inspector de guaneras al Ministerio de Hacienda, en ABNB, MH, t. 96, núm. 17, 30 de enero de 1844, f. 4.

42. Carta de Guillermo Billinghurst al Ministerio de Hacienda, en ABNB, MH, t. 86, núm. 15, 2 de mayo de 1842, ff. 1-2.

43. Estos dos últimos (Billinghurst y Barroilhet) también surgieron de la temprana explotación guanera.

44. Algo que señala Conti (2019: 261), identificando dos grandes categorías de comerciantes en la Cobija de la década de 1840: los intermediarios para compañías extranjeras y los comerciantes de empresas bolivianas.

45. Los locales consideraron «reducidos los comerciantes del país a una exigua y muy contingente utilidad por la excesiva introducción de efectos al interior de la República, demandan sin cesar 
Entre estos, aparecen varios nombres de empresarios y compañías notables que tenían su centro de operaciones en el Litoral. Según la investigación de Conti (2019: 273), Latorre, Lavayen y Cía., Hubert Ainé y Cía., Etcheverry y Cía. y Nicomedes García controlaron gran parte de la entrada de mercancías en el puerto y consiguieron boyantes beneficios con la mediación y reventa. Aunque, sin duda, el capitalista de mayor importancia fue José María Artola, comerciante con el mayor movimiento de capitales de la región (Cajías, 1975: 82; Conti, 2019: 263; Colàs, 2021a: 22), tanto por sus negocios con compañías extranjeras como en calidad de contratista del gobierno boliviano. ${ }^{46}$

Además, las vías de desarrollo ilegales en el Litoral tuvieron una importancia capital, aunque no puedan contabilizarse por la falta de datos estadísticos al respecto. Considero que el robo y contrabandeo de guano pudo ser ya una forma de resistencia local ante la imposibilidad de participar del gran comercio, debido a la existencia de las contratas exclusivas y la legislación excluyente, ya una reacción al despliegue del poder político y al avance de la frontera económica que abanderaban Myers, Gibbs y el gobierno de Ballivián. Como parece lógico, se trató de actividades vistas con preocupación desde el centro, aunque no así desde las autoridades intermedias locales y departamentales.

Es por ello por lo que el robo guanero se convirtió, en la práctica, en un ilegalismo, y no era una preocupación compartida por el poder socioeconómico local que tenía influencia directa en las instancias políticas propias de Atacama (Huber Abendroth, 1997; Barros, 2008). Las autoridades locales repetidamente ignoraron los robos a guaneras y lo justificaron por ser dirigidos a yacimientos inferiores en los que se albergaba producto adulterado, lo cual fue considerado por el gobierno una práctica inconsciente que ponía en peligro el monopolio. ${ }^{47}$ La rapidez en el robo del guano, consecuencia del buen conocimiento del territorio de los grupos de contrabandistas por la presencia de locales en ellos, fue coadyuvada por la lentitud de las autoridades locales, que obviaron esas actividades siempre que se produjeran fuera de Paquica y Angamos, los dos principales yacimientos. La respuesta de la Prefectura del Litoral al gobierno partió siempre de un mismo molde:

una medida que los ponga a cubierto de la ruina que los amenaza» (Redactor de la Cámara de Representantes del año 1846, 1927: 238).

46. «Demostración calculada del precio a que saldrá el azogue de la contrata de D. José María Artola", en ABNB, MH, t. 85, núm. 20, 3 de mayo de 1841. Los datos albergados en el archivo Artola, utilizados en varios artículos sobre la temática empresarial del Litoral, tienen una importancia central para conocer el entramado económico propio de los poderes locales que prosperaron a pesar de ignorar la vía de acumulación que no podía ofrecer el guano por su condición de producto monopolizado.

47. «Por las comunicaciones de V.G. al Ministerio del Interior sabe S.E. que en la bahía de Mejillones fondeó un bergantín, y que los individuos que trajo a bordo saltaron a nuestra costa con el objeto de estraer [sic] huano [sic]; y estrañando [sic], que limitándose únicamente a una notificación de pura seremonia [sic], no se haya empleado la Guarnición del Puerto en contener semejantes abanses [sic], siendo uno de sus principales deberes conserbar [sic] y defender la inbiolavilidad [sic] de nuestro territorio, me ordena prevenir a V.G. para lo succecivo [sic] y por regla jeneral [sic] que cuando se repitan estos atentados y no sedan [sic] a intimaciones oficiales, se les rechase [sic] con la Guarnición a viva fuerza» (Comunicación del Ministerio de Guerra al prefecto del Litoral, en ABNB, Ministerio de Guerra (MG), t. 1847, núm. 8, 4 de octubre de 1847). 
Siendo la sustracción de una materia sin conosido [sic] valor y cuya concurrencia en los mercados de Europa no puede perjudicar los intereses del Estado y de la Sociedad [por estar adulterado o poseer un bajo valor de mercado], prudente le ha parecido [a la prefectura] no agravar a esta con nuebos [sic] desembolsos, ni desprender una pequeña fuerza a una distancia enorme y en embarcaciones menores, que son las únicas que se pueden obtener en Cobija. ${ }^{48}$

El prefecto del Litoral y demás autoridades subalternas fueron duramente criticados por su supuesta connivencia con el contrabandeo guanero. Sus excusas fueron encaradas por el inspector de guaneras, quien argumentó que el prefecto partía del «consepto [sic] equivocado y ecsajerado [sic] [...] respecto a la riqueza inagotable que ofrece el huano [sic] a la República", y se preguntaba «¿en qué funda ciertamente, o en qué hace consistir el Señor Prefecto ese abandono y criminal descuido [en materia de contrabando]? ¿Será porque siendo estranjeros [sic] los contratistas no [le] merecen confianza?».49 En esa afirmación, el inspector apuntó hacia la preferencia de las autoridades locales y regionales para con la explotación guanera local, tanto con comerciantes del nivel de Latrille, como con la extracción tradicional, anunciando un velado choque de modelos con el Estado.

Los implicados directamente en el robo del guano pudieron ser tanto extranjeros como individuos atacameños, chilenos radicados en el Litoral y hasta mayordomos de las guaneras y trabajadores de las sociedades inglesas. Gracias a la deserción de un hombre local de un grupo de contrabandistas, se pudo saber de la contratación de atacameños versados en la extracción de guano por parte de actores piráticos internacionales para cargar ilegalmente buques con destino a Europa,,$^{50}$ y también de la colaboración de los mayordomos con estos, «no cab[iendo] duda que el mayordomo [...] ha[bía] tenido intelijencia [sic] con los Capitanes de dichos Buques». ${ }^{1}$

Al robo por parte de individuos locales se sumó no solo la actuación pirática extranjera, sino también la explotación sistemática de guaneras por parte de nacionales chilenos legitimados por la llamada ley del guano, que permitió la actuación de estos en territorio boliviano. El viajero y explorador alemán Philippi (1860: 104) describió cómo el gobierno chileno había dispuesto la presencia de tropas en ciertos puntos de explotación guanera dentro del territorio boliviano a inicios de la década, y la manera en que, en 1847, los soldados se retiraron ante la proclamación boliviana de propiedad del desierto atacameño (Vargas MansiIla, 2019: 115; Colàs, 2021a: 6). Sin embargo, la ocupación chilena del sur de Atacama durante gran parte de la presidencia de Ballivián fue efectiva y su explo-

48. Comunicación del prefecto del Litoral al Ministerio de Hacienda, en ABNB, MH, t. 102, núm. 40, 23 de enero de 1845, f. $14 \mathrm{v}$.

49. Comunicación del inspector de guaneras al Ministerio de Hacienda, en ABNB, MH, t. 104, núm. 17, 18 de agosto de 1846, ff. 12r-12v.

50. Carta del inspector de guaneras al prefecto del Litoral, en ABNB, MH, t. 102, núm. 40, 16 de enero de 1845, f. 15.

51. Carta de José María Calvo a Gibbs Crawley y Myers Bland, en ABNB, MH, t. 96, núm. 17, 13 de febrero de 1844, f. $10 \mathrm{v}$. 
tación guanera, destacable. Desde la inspección de guaneras se afirmó que «los especuladores chilenos, han estendido [sic] ya sus establecimientos de explotación a Ysla Pascada y hasta el mismo Mejillones o punta de Angames que es la principal huanera [sic] que tenemos al Sud», un peligro intolerable ante el que, esta vez sí, el prefecto del Litoral pareció dispuesto a actuar. «Sea de esto lo que fuere», continuó el inspector, «el hecho solo de venirse hasta Mejillones súbditos chilenos a llevarse el huano que allí ecsiste [sic] es un atentado demaciado [sic] escandaloso» que suponía «el despojo violento de nuestra propiedad con mengua del decoro y dignidad Nacional».52

En definitiva, estas reflexiones demuestran que el proyecto estatal para con el guano no fue aceptado por diversos estratos sociales locales del Litoral boliviano, por lo que, en la práctica, la ilegalidad se convirtió en ilegalismo, y la contrata guanera, en papel mojado. El pirateo, plenamente legitimado por la inacción de las autoridades locales y la participación de individuos atacameños, sorteó la marginación intrínseca en la firma de un monopolio extranjero y se constituyó como herramienta para tratar de superar la difícil coyuntura abierta por la llegada masiva de migrantes chilenos y el interés del gobierno de Chile. Lo que no impide señalar que algunos sectores burgueses pudieron prosperar mediante actividades legales en el Litoral a través del comercio, a pesar de partir de un territorio convertido en margen económico, además de geográfico.

\section{Reflexiones finales}

Haciendo uso del concepto de las formaciones sociales abigarradas de Zavaleta Mercado (1989), considero que la problemática histórica abordada en este trabajo puede ser entendida claramente. Durante la administración de Ballivián, el Litoral quedó separado en tres estratos diferenciados: el superior, con el Estado liberal en construcción de la mano de las empresas británicas del guano; el central, que es el de la burguesía local, boliviana o asentada en el territorio, junto con las autoridades intermedias, que hicieron equilibrios entre las demandas de estos y las del gobierno; y el inferior, el de la población atacameña, en parte desplazada por la llegada de contingentes poblacionales chilenos, que trató de obviar el peso del poder político y económico para dar continuidad a la costumbre territorial de explotación del guano.

En el proceso, el Estado utilizó la legislación para aplicar un peso difícil de sobrellevar sobre los actores de la localidad con el que legitimar la rotura del escenario regional anterior y preparar la llegada del capitalismo internacional en Atacama. Puedo afirmar que el decreto de 20 de febrero de 1842 propició el surgimiento y la progresiva consolidación de un nuevo paisaje económico basado en la potenciación de las exportaciones. Así, la tradición guanera, remarcada por la bioarqueología y por cronistas como Cieza de León o el Inca Garcilaso,

52. Carta del inspector de guaneras al prefecto del Litoral, en ABNB, MI, t. 116, núm. 41, 26 de febrero de 1846. 
fue rota por la llegada del poder liberal, su institucionalización y sus consecuencias. La legislación, pues, pareció tener fuerza suficiente como para imponer el control territorial (Quijada, 2000: 375).

No obstante, el poder central y su aparato legal tuvo que afrontar la renovada relación de la localidad con el guano, que se basó en ignorar su presencia o hacer lo propio con la legislación, deslegitimándola y acabando en la práctica con el monopolio. La connivencia de autoridades intermedias ligadas a los poderes socioeconómicos locales con el robo guanero lo convirtió en un ilegalismo y, en suma, en un choque entre proyectos para el guano y modelos económicos para la construcción estatal. Además, el hecho de que en la región hubiera una larga tradición contrabandista, sumado a la costumbre del uso del guano, hacía difícil el establecimiento exitoso de las compañías guaneras.

En definitiva, a partir del análisis realizado sostengo que, por un lado, la estrategia del Estado con respecto al guano consistió en construir un entramado legal que propiciara el avance del poder central y del capitalismo internacional en el territorio atacameño, junto con el desarrollo de la economía liberal. Y, por otro lado, la estrategia de los grupos de poder local pasó por aprovechar las grietas del poder estatal y económico; aquellos evitaron así la consolidación del monopolio guanero y participaron de la ineficiencia que el Estado en construcción mostró en su relación con los territorios, en este caso en el Litoral. Al final, a la desconfianza del mercado europeo respecto al guano boliviano y la fuerte competencia peruana y africana, se sumó el robo, nacional e internacional, que hizo que el monopolio fuera insostenible.

Por todo ello, el Litoral de la época guanera es un buen ejemplo del proceso de despliegue del poder liberal decimonónico en el contexto latinoamericano, por ser un un territorio marginal del que hasta ese momento solo había interesado su condición costera, y que pasó a observar (y resistirse a) la llegada de la pretensión de control estatal y de beneficio contractual. En parte debido a esa resistencia, el guano no se convirtió en un pilar de un proyecto nacional concreto para Bolivia, pero el fracaso de ningún modo niega la existencia de una lucha política y económica, que confirma la capacidad del Estado en construcción para establecerse como actor principal en el devenir histórico de un margen como el que suponía Atacama.

\section{Bibliografía}

AguiRRE, Miguel María de (1846). Memoria que presenta a las Cámaras Constitucionales de 1846 el Ministro de Hacienda de la República Boliviana. Sucre: Imprenta de Beeche.

Aldunate, Carlos; Castro Rojas, Victoria y Varela, Varinia (2008). «San Bartolo y Cobija: Testimonios de un modo de vida minero en las Tierras Altas y la costa de Atacama». Estudios Atacameños, Antofagasta, 35, págs. 97-118.

ARGuedAS, Alcides (1967 [1922]). Historia general de Bolivia: el proceso de nacionalidad, 1809-1921. La Paz: Puerta del Sol.

BARRAGÁn, Rossana (2007). «Las fronteras del dominio estatal: desigualdad, fragilidad de los pactos y límites de su legalidad y legitimidad». En: ALJOVín DE LOSADA, Cristóbal y 
JaCoBsen, Nils (dirs.). Cultura política en los Andes (1750-1950). Lima: IFEA, págs. 114-131.

BARRAGÁN, Rossana (2009). “"Hegemonías" y "Ejemonías": las relaciones entre el Estado central y las regiones (Bolivia, 1825-1952)». Íconos. Revista de Ciencias Sociales, Quito, 34, págs. 39-51.

BARROS, Alonso (2008). «Identidades y propiedades: transiciones territoriales en el siglo XIX atacameño». Estudios Atacameños, Antofagasta, 35, págs. 119-139.

BenAVENTE, Juan de la Cruz (1846). Contestación a las observaciones que ha publicado el protector de Santiago Villarruel contra el señor coronel don Manuel Isidoro Belzu, en la parte en que son relativas al Juez de Letras del Distrito Litoral. Sucre: Imprenta del Castillo.

BoHoslaVsky, Ernesto y Godoy, Milton (2010). Construcción estatal, orden oligárquico y respuestas sociales: Argentina y Chile, 1840-1930. Buenos Aires: Prometeo Libros.

BoniLLA, Heraclio (1994 [1974]). Guano y burguesía en el Perú. Quito: FLACSO, Sede Ecuador.

Buitrago, Pedro (1844). Memoria que presenta a las Cámaras Legislativas del año de 1844 el ministro del Interior encargado accidentalmente del Ministerio de Hacienda. Sucre: Imprenta del Castillo.

CAJíAs, Fernando (1975). La provincia de Atacama: 1825-1842. La Paz: Instituto Boliviano de Cultura.

CAJíAs, Fernando (1997). «El norte y el sur de Bolivia: Arica y Cobija en los primeros años republicanos». En: BARRAgÁn, Rossana; CAJÍAS, Dora y QAYUM, Seemin (comps.). El siglo XIX: Bolivia y América Latina. Lima: IFEA [en línea]. Disponible en: https://books. openedition.org/ifea/7444.

CAmacho, José María (1896). Compendio de historia de Bolivia. La Paz: Tipografía Comercial.

Chorley, G. P. H. (1981). «The agricultural revolution in Northern Europe, 1750-1880: nitrogen, legumes and crop productivity». The Economic History Review, Londres, 34 (1), págs. 71-93.

CiezA de León, Pedro (1554). Parte primera de La Crónica del Perú. Amberes: En casa de Juan Steelsio.

ColÀs, Pol (2021a). «"Bolivia recibirá el provecho siendo impulsado el solo puerto que posee". Cobija y el Litoral entre el poder local y la administración de José Ballivián (1841-1847)». Estudios Atacameños, Antofagasta, 67, págs. 1-27.

ColÀs, Pol (2021b). «Auge y caída de José Ballivián en Bolivia (1841-1847). Construcción y derribo de la batalla de Ingavi como base legitimadora». Anuario de Estudios Americanos, Sevilla, 78 (1), págs. 257-290.

ConTI, Viviana (2002). Una tierra y tres naciones: el litoral salitrero entre 1830 y 1930. Jujuy: Unidad de Investigación en Historia Regional.

CONTI, Viviana (2008a). «Circulación de mercancías y mercaderes por el espacio surandino (1820-1850)». En: PeREIRA, Teresa e IBÁÑEZ, Adolfo (eds.). La circulación en el mundo andino, 1760-1860. Santiago de Chile: Fundación Mario Góngora, págs. 219-252.

CONTI, Viviana (2008b). «Una empresa mercantil familiar en el espacio económico surandino: Tezanos Pinto y Cía., 1704-1854». En: BANDIERI, S. et al. Las escalas de la historia comparada. Tomo II. Empresas y empresarios. La cuestión regional. Buenos Aires: Miño y Dávila, págs. 29-55. 
Contı, Viviana (2019). "Comerciantes y redes desde el puerto boliviano de Cobija». Revista del Instituto Riva-Agüero, Lima, 4 (1), págs. 241-282.

CONTI, Viviana y SICA, Gabriela (2011). «Arrieros andinos de la colonia a la independencia. El negocio de la arriería en Jujuy, Noroeste Argentino". Nuevo Mundo, Mundos Nuevos. Débats, págs. 20-37. DOI: https://doi.org/10.4000/nuevomundo.60560.

CoRTÉs, Manuel José (1861). Ensayo sobre la historia de Bolivia. Sucre: Imprenta de Beeche. CRAIG, Robin (2003). British tramp shipping, 1750-1914. Liverpool: Liverpool University Press.

CuSHMAN, Gregory T. (2018). Los señores del guano. Una historia ecológica global del Pacífico. Lima: IEP.

DemÉLAS, Marie-Danielle (2003). La invención política: Bolivia, Ecuador, Perú en el siglo XIX. Lima: IFEA.

FIFER, J. Valerie (1972). Bolivia: land, location, and politics since 1825. Cambridge: Cambridge University Press.

FouCAULt, Michel (2009 [1976]). Vigilar y castigar: nacimiento de la prisión. Ciudad de México: Siglo XXI.

GALAZ-MANDAKOVIC, Damir (2017). «Gatico: capitalismo cuprífero, catástrofes y borradura de una ciudad (1832-1940)». Colecciones Digitales, Subdirección de Investigación DIBAM, Santiago de Chile, págs. 1-23.

Galaz-Mandakovic, Damir y Owen Palma, Eduardo (2015). Hermanos Latrille: impronta en el desierto. Tocopilla: Retruécanos Ediciones.

GARCILASO DE LA VEGA, Inca (1959 [1609]). Comentarios reales. Lima: Librería Internacional del Perú.

Godoy, Milton (2013). «Donde el cóndor de los Andes apenas se posa tímido. El puerto de Cobija y el litoral de Atacama en el informe del coronel Quintín Quevedo, julio de 1867». Estudios Atacameños, Antofagasta, 46, págs. 127-144.

Gootenberg, Paul (1989). Between silver and guano: commercial policy and the state in post-independence Peru. Princeton: Princeton University Press.

ILLANES, María Angélica (1997). «Azote, salario y ley. Disciplinamiento de la mano de obra en la minería de Atacama (1817-1850)». Proposiciones, Santiago de Chile, 19, págs. 90-122.

IRUROZQUI, Marta (ed.) (2005). La mirada esquiva. Reflexiones históricas sobre la interacción del Estado y la ciudadanía en los Andes (Bolivia, Ecuador y Perú), siglo XIX. Madrid: CSIC.

IRUROZQUI, Marta (2018). Ciudadanos armados de ley. A propósito de la violencia en Bolivia, 1839-1875. La Paz: Plural / IFEA.

JULIEN, Catherine Jean (1985). "Guano and resource control in sixteenth-century Arequipa». En: Shozo, Masuda; ShimadA, Izumi y MorRIs, Craig (eds.). Andean ecology and civilization: an interdisciplinary perspective on Andean ecological complementary. Tokio: University of Tokio Press, págs. 185-231.

KNUDSon, Kelly J. (2007). «La influencia de Tiwanaku en San Pedro de Atacama: Una investigación utilizando el análisis de los isótopos del estroncio». Estudios Atacameños, Antofagasta, 33, págs. 7-24.

LANGER, Erick D. (2018). «Integración económica en el desierto de Atacama antes y después de la guerra del Pacífico». Anuario de Estudios Bolivianos Archivísticos y Bibliográficos, Sucre, 25, págs. 235-254. 
Letelier Cosmelli, Javiera (2016). «Entre la costa de Cobija y Tierras Altas. El tráfico arriero a inicios de la República boliviana». Diálogo Andino, Arica, 49, págs. 225-234.

Letelier Cosmelli, Javiera y Castro Rojas, Victoria (2017). "Changos en el Puerto de Cobija. Transformaciones sociales durante el siglo XIX». Revista Española de Antropología Americana, Madrid, 47, págs. 127-142.

LetelieR Cosmelli, Javiera y CAStRo RoJAs, Victoria (2019). «Imaginarios del Puerto Lamar desde 1825 a 1877». Chungará. Revista de Antropología Chilena, Arica, 51 (1), págs. 155-166.

LETTIERI, Alberto (2005). «La cuestión del régimen político en los proyectos de la nación argentina (mediados del siglo XIX)». Revista de Indias, Madrid, LXV (234), págs. 535562.

MARTínEZ, José Luis (1985). «Información sobre el comercio de pescado entre Cobija y Potosí, hecha por el corregidor de Atacama, don Juan de Segura (19 de julio de 1591)». Cuadernos de Historia, Santiago de Chile, 5, págs. 161-171.

MatheW, William M. (2009). La firma inglesa Gibbs y el monopolio del guano en el Perú. Lima: Banco Central de Reserva del Perú - IEP.

MÉndeZ-QuiRós, Pablo y SÁnchez, Tamara (2009). «El ciclo del guano en el Pacífico sur, una epopeya olvidada (1860-1960)». XVIII Congreso Nacional de Arqueología Chilena. Valparaíso: Universidad de Chile.

NEWELL, William H. (1973). «The agricultural revolution in nineteenth-century France». The Journal of Economic History, Cambridge, 33 (4), págs. 697-731.

PHILIPPI, Rodolfo Amando (1860). Viage al desierto de Atacama hecho de orden del Gobierno de Chile en el verano 1853-54. Halle: Eduardo Antón.

PINTO VAlleJos, Julio (1993). «Cortar raíces, criar fama: el peonaje chileno en la fase inicial del ciclo salitrero, 1850-1879». Historia, Santiago de Chile, 27, págs. 425-447.

Pinto Vallejos, Julio y Valdivia Ortiz de ZÁrate, Verónica (1997). «Peones chilenos en tierras bolivianas: la presencia laboral chilena en Antofagasta (1840-1879)». En: BARRAGÁN, Rossana; CAJÍAS, Dora y QAYUM, Seemin (comps.). El siglo XIX: Bolivia y América Latina. Lima: IFEA [en línea]. Disponible en: https://books.openedition.org/ifea/7412.

PLATT, Tristan (2016). «Tiempo, movimiento, precios. Los caminos del azogue español de N. M. Rothschild entre Almadén, Londres y Potosí 1835-1848». Diálogo Andino, Arica, 49, págs. 143-165.

QUIJADA, Mónica (2000). «Nación y territorio: La dimensión simbólica del espacio en la construcción nacional argentina. Siglo XIX». Revista de Indias, Madrid, LX (219), págs. 373-394.

RAVEST MorA, Manuel (2008). «La casa Gibbs y el monopolio salitrero peruano: 1876-1878». Historia, Santiago de Chile, 41 (1), págs. 63-77.

Redactor de la Cámara de Representantes del año 1846 (1927). La Paz: Litografías e Imprentas Unidas.

SzPAK, Paul, et al. (2012). «Influence of seabird guano and camelid dung fertilization on the nitrogen isotopic composition of field-grown maize (Zea mays)». Journal of Archaeological Science, Ámsterdam, 39, págs. 3721-3740.

Uribe RodríGuez, Mauricio, et al. (2016). «San Pedro de Atacama y la cuestión Tiwanaku en el norte de Chile: impresiones a partir de un clásico estudio cerámico y la evidencia bioarqueológica actual (400-1000 d.C.)». Chungará, Arica, 48 (2), págs. 173198. 
VARGAS MANSILLA, Stephanie (2019). «Desde afuera. Las dinámicas fronterizas de la provincia de Atacama y la construcción del territorio nacional (1840-1866)». Ciencia y Cultura, La Paz, 42, págs. 99-119.

Villalobos, Sergio (1979). La economía de un desierto: Tarapacá durante la Colonia. Santiago de Chile: Ediciones Nueva Universidad.

Zavaleta Mercado, René (1978). «Las formaciones aparentes en Marx». Historia y Sociedad, Ciudad de México, 18 (2), págs. 3-25.

Zavaleta Mercado, René (1989). El Estado en América Latina. La Paz: Los Amigos del Libro.

Fecha de recepción: 27 de mayo de 2021

Fecha de aceptación: 12 de agosto de 2021

Fecha de publicación: 22 de diciembre de 2021 